\title{
Under-reporting of gossypiboma in a third-world country. A sociocultural view
}

\author{
David Omoareghan Irabor \\ Department of Surgery, University College Hospital Ibadan, Ibadan, Nigeria; dirabor@comui.edu.ng, irabordavid@yahoo.com
}

Received 9 November 2011; revised 2 December 2011; accepted 19 December 2011

\section{ABSTRACT}

The paper looks at the reason for the low reportage of retained abdominal packs following an abdominal operation in a third world country like Nigeria. It is generally agreed that this unfortunate situation is under-reported. The reason for under-reporting is now given a socio-cultural perspective. Fear of litigation does not seem to be paramount here like it would be in the western (developed) world. Other explanations like fear of being made a scapegoat for something which may be due to spiritual attacks may be more important. The paper concludes by recommending that the removal of impediments to disclosure of this adverse surgical event will lie in education, discouragement of scapegoatism and improvement in hospital services in the third world.

Keywords: Gossypiboma; Retained Abdominal Pack; Under-Reporting

\section{INTRODUCTION}

The retained abdominal sponge after an abdominal operation has been in existence ever since human beings began surgical operations on their kind. It has been known by other appellations such as Gossypiboma, Textiloma, Muslinoma and Gauzoma [1]. The incidence is understood to be about 1 in every 1000 to 1500 abdominal operations $[2,3]$. However the general feeling is that this is probably less than the true incidence due to reluctance of those involved to report the occurrences [3]. So, why should there be deliberate under-reporting? No doubt the medico-legal implications play a role, but in the third-world, especially Nigeria where patients hardly sue their doctors, why is this still not reported accurately? This paper looks at the peculiar socio-cultural setting of a third-world country in a bid to understand the under-reporting of gossypiboma.

\section{THE DRAMA}

In a society where the medical practitioner is seen as all powerful [4] (especially those who practice surgery), the knowledge that a serious error by such a "deity" (leaving behind a piece of cloth or an instrument inside a patient's body cavity) can occur gives rise to vicious satisfaction among the populace. What probably goes through the layman's mind is: "So, they (the doctors) can be human after all; maybe they are not as knowledgeable or omnipotent as they look".

Newspaper reporters also give it front page billing [5-7]: several headlines like "Horror! Surgeon forgets scissors in belly of patient" (usually artery forceps, but what does the reporter know or care?) or "Hospital shocker; doctor leaves napkin in woman's belly" (That's what a journalist prefers to call a laparotomy pack or sponge).With this kind of negative publicity some hospital administrators are influenced to mete out sanctions instead of trying to understand the circumstances involved, and looking at ways to reduce the occurrence [2] e.g by improving their own services.

\section{THE CULTURE}

When a patient is re-operated upon because of persistent symptoms post laparotomy and a retained pack is found, the unwritten rule is that "it was never there". As such, that information never enters the operation notes or the operations register. Many times the primary surgeon is not even at surgery especially if the patient happened to have had a Caesarean section and developed abdominal distension post operatively. The surgeons are called in; they take over the case and re-explore the patient. When the cause is a gossypiboma everyone in theatre agrees (via an unwritten rule) that such information must not leave the theatre in order to protect the reputation and professsional integrity of the obstetrician. Consequently, the main culprit never gets to know about his mistake and when, out of curiosity he asks about the operation findings, he/she is usually told that an organized abscess was found. This is what the operation notes will reflect and the operations 
register will state that drainage/evacuation of an organized abscess was performed.

Culturally, this is an example of "looking out for one another" [4] and you expect that your own back will also be covered when this unlucky incident happens to you [4]. Nobody wants to be the one responsible for damaging the career of another colleague. If the patient is not morbidly or mortally affected by the incident, why should the integrity and reputation of a colleague be damaged? Whistle-blowers (or snitches) are traditionally despised in the community $[8,9]$ and for as long as you live or work in the community, fingers will be pointed and tones will be hushed when you are nearby as being the person who ruined Dr XYZ's career. The whole scenario reminds one of the "Omerta" the culture of "silence" by the Cosa Nostra. Indeed for those in government employment, it's usually a case of "them against us"; employer against employee.

\section{SCAPEGOATISM}

A senior registrar (SR) who performed an emergency operation on a multiply-injured patient with a liver laceration had the misfortune of leaving an abdominal pack behind and after 4 weeks of the patient still manifesting abdominal symptoms had to re-explore that abdomen. In spite of the advice of his consultant that he should not do the re-exploration without him, he went ahead without his consultant and found a laparotomy pack which he then removed. He proceeded to write in the case-file and operations register that a laparotomy pack was found and extracted. The information in the case-file was leaked to the husband of the patient and almost got to the press. The hospital authorities got to know because the husband caused a scene; set up a kangaroo tribunal and suspended both the SR and his consultant for 6 months. All who heard lamented that the inexperience (socio-culturally and not surgically) of the SR led to his and his consultant's predicament. If his consultant had been there they opined, he would not have recorded that kind of thing; nothing like that would have appeared on record.

\section{THIRD WORLD PROBLEMS}

Emergency procedures have been identified as a major factor in the incidence of gossypiboma [3]. In developing countries, power outages are major challenges [10] and these occur often during emergency operations, thus a surgeon who was trying to control a bleeding vessel at that time may need to pack the area involved with gauze-packs while waiting for electricity to be restored. Sometimes the surgeon is handed 2 packs instead of one (the scrub nurse can make mistakes in the dark). When the electricity is finally restored the surgeon removes only one pack while the other could have migrated un-knowingly.
Very few hospitals in the $3^{\text {rd }}$ world have gauze packs that can be picked on plain abdominal x-rays. (A registered brand is Raytec). To save costs, many hospitals in Nigeria buy big rolls of gauze and give the theatre nurses the task of cutting and folding the gauze into sponges so that they can be sterilized for theatre use. The nurses also pack these into bundles of 5 (i.e. 5 gauze sponges per bundle). Sometimes human error may creep in, causing bundles to be greater or lesser than 5. So a lot of confusion may ensue during swab counts; a swab may be said to be missing when in truth it isn't or it may said to be complete when indeed one is retained. The latest of the sponge technology aimed at preventing retention is the Clearcount Smartsponge system [1]. The Smartsponge System uses a small, passive Radiofrequency Identification (RFID) tag securely embedded in each sponge. This ensures that by the end of the operation a monitor will show if sponges are complete or not. It is not likely that this technology will be available to third-world hospitals for a long time.

\section{THE SPIRITUAL ASPECT}

In majority of cases of gossypiboma, swab counts usually are said to be correct [1]. So looking at it from the spiritual angle, the person or persons involved may surmise that this may be the work of their enemies. These ill-wishers cannot get at you any other way so they supernaturally conjure gauze sponges into your patients. In many parts of Africa, misfortune has a lot of supernatural undertones [11], with witches or evil spirits being the causative elements [12]. I have been present at some situations where the targeted victims are not even the doctors or nurses but the unfortunate patients. In one case it was rumored that the husband of a female patient who had a retained gauze pack wanted to marry another woman and as such he ensured his wife would not leave the hospital alive through supernatural means. The other patient had a small gauze sponge left within her right breast after a breast lump excision. This was discovered after she had persistent pain and swelling 2 weeks after the excisional biopsy. She completely exonerated the doctor as she claimed that, in a dream, it was revealed to her that her enemies would attack her via her organs of femininity.

In Africa, there is a lot of belief in the supernatural or the spiritual as we like to call it $[11,12]$.

\section{SEQUELAE OF GOSSYPIBOMA}

Retained abdominal sponges may cause symptoms of abdominal pain, intestinal obstruction or they may be spontaneously extruded either through the operation wound or by eroding into the intestines and passing out with faeces, [13-15]. Some may remain sterile and encapsulated and cause no symptoms for years, being of little harm to the patient $[1,16]$. Others may be the cause of intra-abdominal 
abscess, persistent enterocutaneous fistula or persistent discharging sinuses [14].

By and large, apart from the discomfort to a patient from a repeat operation, and the stigma to the surgeon, most reports show a low mortality for this condition $[1,16]$.

\section{MEDICAL ERROR OR COLLATERAL DAMAGE?}

Could the occurrence of Gossypiboma be termed a medical error or could it just be an unpalatable consequence of the increased volume of work that surgeons have to contend with in the third world? This applies to increased emergency surgery from road traffic accidents which has reached epidemic proportions in the third-world [17].

Gossypiboma is undoubtedly a medical error and one is duty-bound (ethically) to disclose this [18]. However if the subsequent reaction of the public and employers towards such a medical error is akin to a situation in which the wrong limb was amputated or one ureter was inadvertently tied up during a hysterectomy, then it would make it understandable (but not justifiable) why the dramatis personae are not anxious to disclose it. The author does not support under-reporting of gossypiboma but when a surgical team has had a correct sponge count during surgery which then turned out to be incorrect eventually; that does not make the operating team negligent. Especially in the developing world where extraneous factors may interfere with surgical practice.

It is understood that currently, even in spite of all the new developments in sponge science, there are no concrete methods of completely preventing retained sponges [1].

Retained sponges have for too long been viewed as the prima facie evidence of negligence by the doctor in charge. It has been recommended that education of the general populace regarding the circumstances and exigencies of some surgical operations may show that the approach of litigation in most cases is not fair [2].

\section{CONCLUSION}

When we demystify the situation, remove the stigma attached, educate the populace about circumstances which may lead to this problem, discourage knee-jerk scape-goatism approaches by hospital administrators and improve hospital theatre services, then, maybe, we may have honest reports of the true incidence of gossypiboma in Africa.

\section{REFERENCES}

[1] Stawicki, S.P., Evans, D.C., et al. (2009) Retained surgical foreign bodies: A comprehensive review of risks and preventive strategies. Scandinavian Journal of Surgery, 98, 8-17.

[2] Hyslop, J.W. and Maull, K.I. (1982) Natural history of the retained surgical sponge. Southern Medical Journal, 75, 657-660. doi:10.1097/00007611-198206000-00006

[3] Mefire, A.C., Tchounzou, R., et al. (2009) Retained sponge after abdominal surgery: Experience from a third world country. The Pan African Medical Journal, 2, 10.

[4] Irabor, D.O. and Omonzejele, P.F. (2009) Local attitudes, moral obligation, customary obedience and other cultural practices: Their influences on the process of informed consent for surgery at a tertiary institution in a developing country. Developing World Bioethics 9, 34-42. doi:10.1111/j.1471-8847.2007.00198.x

[5] Millenson, M.L. (2002) Pushing the profession: How the news media turned patient safety into a priority. Quality and Safety Health Care, 11, 57-63. doi:10.1136/qhc.11.1.57

[6] Lupton, D. and McLean, J. (1998) Representing doctors: Discourses and images in the Australian press. Social Science and Medicine, 46, 947-958. doi:10.1016/S0277-9536(97)10013-2

[7] Garg, M. and Aggarwal, A.D. (2010) A review of medicolegal consequences of Gossypiboma. Journal of Indian Academy of Forensic Medicine, 32, 358-361.

[8] Uys, T. (2008) Rational loyalty and whistleblowing: The South African context. Current Sociology, 56, 904-921. doi:10.1177/0011392108095345

[9] Perks, S. and Smith, E.E. (2008) Employee perceptions regarding whistle-blowing in the workplace: A South African perspective. South African Journal of Human Resource Management, 6, 15-24

[10] Bamgboye, E.L. (2003) Hemodialysis: Management problems in developing countries, with Nigeria as a surrogate. Kidney International, 63, S93-95. doi:10.1046/j.1523-1755.63.s83.19.x

[11] Ezeome, E.R. and Anarado, A.N. (2007) Use of complementary and alternative medicine by cancer patients at the University of Nigeria Teaching Hospital Enugu, Nigeria. BMC Complementary and Alternate Medicine, 7, 28. doi:10.1186/1472-6882-7-28

[12] Pool, R. (1994) On the creation and dissolution of ethnomedical systems in the medical ethnography of Africa. Africa: Journal of the International African Institute, 64, 1-20. doi:10.2307/1161092

[13] Fadiora, S.O., Olatoke, S.A., Bello, T.O., Adeoti, M.L. and Agodirin, S.O. (2004) Intestinal obstruction from a forgotten artery forceps: A case report. West African Journal of Medicine, 23, 330-331.

[14] Gencosmanoglu, R. and Inceoglu, R. (2003) An unusual cause of small bowel obstruction: Gossypiboma-case report. BMC Surgery, 3, 6. doi:10.1186/1471-2482-3-6

[15] Agarwal, A.K., Bhattacharya, N., Mukherjee, R. and Bora, A.A. (2008) Intraluminal gossypiboma. Pakistan Journal of Medical Sciences, 24, 461-463.

[16] Cima, R.C., Kollengode, A., Garnatz, J., Storsveen, A., Weisbrod, C. and Deschamps, C. (2008) Incidence and characteristics of potential and actual retained foreign object events in surgical patients. Journal of the American College of Surgeons, 207, 80-87.

doi:10.1016/j.jamcollsurg.2007.12.047 
[17] Nantulya, V.M. and Reich, M.R. (2002) The neglected epidemic: Road traffic injuries in developing countries. British Medical Journal, 324, 1139-1141. doi:10.1136/bmj.324.7346.1139
[18] Edwin, A.K. (2009) Non-disclosure of medical errors an egregious violation of ethical principles. Ghana Medical Journal, 43, 34-39. 